\title{
Syphilis in China: the great comeback
}

\author{
T Hesketh ${ }^{1}, \mathrm{XJ} \mathrm{Ye}^{2}$, and WX Zhu ${ }^{3}$ \\ ${ }^{1}$ UCL Centre for International Health and Development, Institute of Child Health, University College London, London, UK; ${ }^{2}$ Institute of Family \\ and Social Medicine, Zhejiang University, Hangzhou, PR China; and ${ }^{3}$ School of Law and Public Policy, Zhejiang Normal University, Jinhua, PR \\ China.
}

\section{Correspondence \\ Dr T Hesketh, UCL Centre for International Health and \\ Development, Institute of Child Health, University College London, 30 Guilford Street, London WC1N $1 \mathrm{EH}, \mathrm{UK}$. \\ E-mail: t.hesketh@ich.ucl.ac.uk}

Received 14 June 2007

Revised 11 December 2007

Accepted 14 January 2008

\begin{abstract}
China is currently witnessing a major resurgence of syphilis from the elimination of the disease in the 1960 s to 5.3 per 100,000 people incidence in 2000-2005. The reasons for the elimination and subsequent resurgence of syphilis in China lie at the heart of much public health debate, highlighting both the relationship between politics and public health, and the role of government in controlling disease. Were the Draconian measures to control syphilis during the early Mao years a price worth paying for the effective control? Is the recent resurgence of syphilis an inevitable consequence of economic development and greater freedom for the individual, which will ultimately lead to better health for the majority of the population? Could tougher control measures such as those of the early Mao years be re-introduced in the current social and economic climate in China? In this review, we briefly chart the history of the syphilis epidemic in China, its elimination in the 1960s, and its gradual resurgence in the past two decades. We explore the reasons for this resurgence, and we conclude with a discussion on the options for control.
\end{abstract}

\section{Introduction}

Syphilis has been a major cause of mortality and morbidity for around 500 years. ${ }^{1}$ It is caused by the bacterium Treponema pallidum, which is transmitted sexually, from mother to foetus, and more rarely through injecting drug use. $^{2}$ The symptoms of syphilis can be wide ranging, often being confused with other conditions, and may also be asymptomatic, making diagnosis a particular challenge. The disease classically presents in three distinct stages. The primary stage involves the formation of a genital chancre or ulcer, which is highly contagious. Around one-quarter of these cases go on to the secondary stage, which causes a range of symptoms including hair loss, fever, rashes, joint pains, and genital warts, which are also contagious. If left untreated, the condition can go on to the tertiary stage, which consists of chronic and severe neurological, and cardiovascular damage leading to death. ${ }^{3}$ Syphilis infection during pregnancy leads to foetal loss, stillbirth, neonatal disease, and long-term deformities. ${ }^{4}$ The highly contagious nature of the disease makes detection and treatment crucial. ${ }^{5}$ Treatment is with drugs of the penicillin group, which are widely available.

There are also important interactions between syphilis and HIV. The presence of syphilis raises the viral load in HIV-infected individuals, ${ }^{6}$ and there is evidence that syphilis enhances the transmission of HIV. ${ }^{7}$ Early detection and treatment of syphilis can, therefore, have a significant impact on the sexual transmission of HIV.

\section{The elimination of syphilis}

Syphilis was originally introduced to China in the 1500 s by Portuguese traders. ${ }^{8}$ By the time figures became available in the 1940s, it is estimated that $5 \%$ of all urban dwellers and $3 \%$ of rural peasants were infected with syphilis, with over $50 \%$ of prostitutes across the country infected with the disease. ${ }^{9}$ Its spread was driven by a rampant commercial sex sector, and very limited available and effective treatments.

When Mao Ze Dong came to power in 1949, one of his top priorities was to address the massive disease burden of the impoverished population. ${ }^{10}$ The creation of a public health infrastructure and the provision of virtually universal access to free health care were just two of Mao's extraordinary achievements in the early years. The elimination of sexually transmitted disease (STD) was another. STDs were portrayed as a consequence of evil western influences, fitting perfectly with the patriotic fervour of the time. ${ }^{11}$ By 1954 , a nationwide STD control programme had been introduced. Thousands of health workers were trained to recognise the signs and symptoms of STDs, screening was introduced, and free antibiotics were made widely available. ${ }^{8}$ Brothels were closed and prostitutes were incarcerated for compulsory

OPEN This is an Open Access article distributed under the terms of the Creative Commons Attribution licence which permits unrestricted use, distribution, and open - access reproduction in any medium, provided the original work is properly cited. 
re-education programmes. All this occurred against a background of prohibition of pre- and extramarital sex, in a country that was virtually closed to the outside world. By 1964, the Chinese proclaimed that syphilis had been eradicated in mainland China. ${ }^{12}$ The successful campaign against STDs is one of the great public health successes in world history, showing how high-level political commitment, combined with community participation and health promotion, can eliminate a major disease.

\section{The return of syphilis}

China remained syphilis-free for around two decades. The first cases of syphilis for over 20 years were reported in 1979 soon after Deng Xiao Ping instigated his radical economic reform programme. ${ }^{13}$ This led the Ministry of Health to develop a surveillance system for STDs that was functioning by 1987 and continues to this day, providing valuable data on secular trends. It consists of mandatory case reporting from STD clinics and hospitals across the country. To increase the accuracy, a network of sentinel surveillance sites was also established in areas with known high rates of STDs. ${ }^{14}$

This sentinel surveillance provides valuable data on trends. From 1989-1998, there was an increase in all STDs, but a massive 20-fold increase in syphilis over the time period, compared with a mere 2.6-fold increase in gonorrhoea. ${ }^{15}$ Incidence rose from 0.2 per 100,000 in 1989 to a peak of 6.5 per 100,000 in 1999. From 2000 to 2005, the incidence averaged $5.1-5.8$ per 100,000 per year. ${ }^{16}$ The incidence has been consistently higher in men than in women but the gap had narrowed to around 1.3:1 in 1998 and has remained there. ${ }^{15}$ These figures compare with a syphilis incidence in the USA of 3 per 100,000 in 2005, up 11\% from 2004, after an all-time low in 2000, with much of the increase in men who have sex with men (MSM). ${ }^{17}$ Other Asian nations, such as Thailand and India, are generally seeing a decline or little change in syphilis reports, ${ }^{18}$ although as elsewhere these almost inevitably underestimate the true incidence, because symptomatology can be non-specific, cases may be missed, and physicians (especially private practitioners) cannot be relied on to report.

Chinese sentinel surveillance also shows clear geographical differences, with higher incidences in not only the more prosperous south-eastern coastal regions-Shanghai, Zhejiang, Fujian provinces-but also in poorer inland Guangxi. ${ }^{16}$ The mean age of people with reported syphilis was relatively old at 37 years, compared with $25-28$ years in the USA. ${ }^{17}$ A further important finding is a very rapid rise in reports of congenital syphilis from 0.01 cases per 100,000 live births in 1991 to 19.7 in $2005 .{ }^{16}$ This is equivalent to 3400 cases of congenital syphilis per year. As syphilis also leads to spontaneous abortion and stillbirth, ${ }^{4}$ this figure certainly underestimates the total disease burden.

A number of other studies, carried out in high-risk groups as part of mandatory testing procedures, confirm these marked upward trends. Lin et al. ${ }^{14}$ have carried out the only systematic review of incidence studies. The 174 studies (169 from the Chinese literature) were categorised by population subgroup, as shown in Table 1. The prevalence in the lowrisk groups, which approximate the general population, were all below 1\%: $0.3 \%$ in food and service employees undergoing routine employment examinations, $0.45 \%$ in women attending antenatal clinics, $0.66 \%$ in premarital examination attendees, and $0.37 \%$ in voluntary blood donors. Note that HIV prevalence in the general population is less than $0.1 \% .{ }^{19}$ In high-risk groups, the prevalence was highest (14.6\%) in MSM and incarcerated female sex workers (FSWs; $12.5 \%)$. Upward trends in these two groups were also highest, $1.4 \%$ increase per year in the incarcerated FSWs and $4.5 \%$ per year in MSM. It should be noted that the figure for incarcerated sex workers probably overestimates the figure for all sex workers in China, as FSWs who are arrested are more likely to be poor, uneducated street prostitutes. They are at higher risk of STDs than those working in brothels, massage parlours, and bars, who constitute the majority of FSWs in China. ${ }^{20,21}$ The latter are more likely to adhere to safer sexual practices and are less likely to be arrested. $^{22}$

Since Lin's review was published, there have been further studies of syphilis and HIV prevalence among FSWs and MSM. A consistent finding is the relatively high prevalence of syphilis in comparison with HIV, which is in sharp contrast to the situation in many other countries. ${ }^{23,24}$ Large studies of MSM in the major Chinese cities show that in Beijing 3.2\% of the MSM studied were HIV positive and

Table 1 Summary of syphilis prevalence studies from 2000 to 2005 (adapted from Lin et al. ${ }^{14}$ )

\begin{tabular}{lcc}
\hline Population subgroup & No. of studies & $\begin{array}{c}\text { Median syphilis prevalence } \\
\text { (interquartile range) }\end{array}$ \\
\hline Food and service & 19 & $0.3(0.2-0.5)$ \\
Antenatal women & 19 & $0.45(0.29-0.60)$ \\
Premarital examination attendees & 20 & $0.66(0.31-1.43)$ \\
Volunteer blood donors & 39 & 0.04 \\
Commercial blood donors & 7 & $0.37(0.20-0.65)$ \\
Incarcerated female sex workers (FSWs) & 21 & $2.86(1.7-9.9)$ \\
Incarcerated FSW clients & 21 & $12.5(4.9-17.8)$ \\
Men who have sex with men (MSM) & 4 & $0.83(0.62-1.30)$ \\
Incarcerated drug users & 8 & $14.6(10.6-18.7)$ \\
\hline
\end{tabular}


$11.2 \%$ syphilis seropositive; ${ }^{25}$ in Shanghai 1.47 and $13.5 \%$, respectively; ${ }^{26}$ in Guangzhou 0 and $10.5 \%$, respectively; ${ }^{27}$ and in Nanjing 0 and $6.9 \%$, respectively. ${ }^{28}$ Similarly in FSWs, a Yunnan study reported an HIV prevalence of $0.6 \%$, syphilis of $15.7 \%$, and gonorrhoea of $2.0 \% ;^{29}$ and in Sichuan a study found an HIV prevalence $0.5 \%$ with syphilis of $11 \%{ }^{30}$ As with low-risk populations, the prevalence of syphilis is over 10 times higher than that of HIV.

With China's population estimated at over 1.3 billion, the burden of disease from syphilis is huge. Accurate numbers of individuals in high-risk groups are unclear, especially given that these activities are officially illegal, but estimates range from 2.8 to 4.5 million for sex workers, 1.8 to 2.9 million injecting drug users (IDUs), and 3.6 to 7.1 million high-risk MSM. ${ }^{19,31}$ There is some overlap between these groups and varying syphilis prevalence among them in different parts of the vast country. ${ }^{14}$ Extrapolating from estimates for 2000-2005 from Lin's review, the most conservative figures would put the number of infected sex workers at 200,000, IDUs at 250,000, and MSM at 400,000.

\section{The reasons for the resurgence}

The underlying reason for the resurgence in syphilis in China is massive societal change. But first there is an intriguing biological explanation. ${ }^{32}$ This stems directly from the very success of the earlier eradication programme. It is known that syphilis infection causes an immune response, which reduces the probability of re-infection or modifies the course of the disease. A study of secular trends in syphilis incidence in the USA over a 50-year period revealed 10-year cycles of higher disease incidence, which were attributed to loss of protective immunity. ${ }^{33}$ It has been argued that the elimination of syphilis from mainland China for around two decades created a highly susceptible population with resulting increasing likelihood of disease transmission. ${ }^{32}$ The fact that gonorrhoea has not increased to the same degree lends weight to this argument, because gonorrhoea does not confer immunity in the same way. This may also explain why China has seen such a massive resurgence of syphilis when other Asian nations witnessing similar change in sexual behaviour, have not.

The social causes for the resurgence in syphilis are underpinned by the profound economic and social change in the past two decades that have resulted in a shift from a centralised, highly controlled, socialist economy to a booming, often unregulated, capitalist system. As a consequence of this, a number of changes have taken place that are now combining to drive the syphilis epidemic. These are (i) changes in sexual attitudes and behaviours, (ii) the new mobility of the population, and (iii) privatisation of the healthcare system with underinvestment in public health infrastructure.

\section{Sexual attitudes and behaviours}

There has been a gradual but definite shift in sexual attitudes and behaviours from the monogamous imperatives of the
Mao years. The rise in syphilis itself, of course, shows that there must be increased levels of partner exchange compared with those previously observed. ${ }^{34}$ The fact that syphilis peaks in individuals in their late 30s also suggests that this is the result of a partner exchange after marriage (around 95\% of Chinese marry in their 20s). ${ }^{35}$ It has been observed in China that non-monogamous sex, and, especially paid sex, is far more common as an extramarital activity than a premarital one. ${ }^{34}$ The growth in the sex industry over the past two decades, and especially the acceptance of sex being sold in non-traditional venues, such as barbershops and karaoke bars, has particularly contributed to the spread of syphilis. The number of sex workers is estimated to have increased 10 -fold over the past two decades to the current estimate of 3-4 million. ${ }^{19}$ There are also concerns that the sex industry will continue to grow because of the emerging problem of excess men, ${ }^{36,37}$ which has resulted from a combination of the traditional Chinese preference for male offspring, the One Child Policy, and easy access to sexselective technology. ${ }^{38}$ This has led to a sex ratio of around 117 male births to 100 female births per year, with around 20 million excess men of reproductive age in the next two decades, ${ }^{39}$ with increased demands for commercial sex almost inevitable. ${ }^{37}$

Studies of sexual behaviour among Chinese populations are still not common, partly as a hangover from the years of sexual repression, and partly as because of traditional reluctance to discuss sexual issues. The few studies that address premarital and extramarital sex show that it has increased, dramatically, in some urban areas, ${ }^{34}$ but that traditional values persist, and China has not reached the levels of permissiveness seen in Western countries. For example, of 986 sexually active migrants in Shanghai only $14 \%$ had had more than one sexual partner and $31 \%$ had had premarital sex. ${ }^{40}$ A study among women in Hainan island showed $15 \%$ had had premarital sex but none had had extramarital sex, ${ }^{41}$ and a study among market vendors in Hefei, a large eastern city, showed $28 \%$ had had premarital sex. ${ }^{42}$ Other studies have shown higher figures. For example, $52 \%$ of those questioned in a study in rural Anhui Province had had premarital sex. ${ }^{43}$ Studies among university students show relatively low levels of sexual activity: a large study of students in Ningbo, eastern China, showed that $17 \%$ of men and $8 \%$ of women reported ever having sex. ${ }^{44}$ In Beijing, $14 \%$ of unmarried male students and $9 \%$ of unmarried female students had had sexual intercourse. ${ }^{45}$ A study among university students in Shanghai showed that $45 \%$ of the men and $27 \%$ of the women thought that premarital sex was acceptable. $^{46}$

Homosexuality, which had previously been totally unacceptable in virtually all echelons of society, is now achieving a level of acceptability in most urban areas with gay clubs and bars springing up in most cities. ${ }^{47}$ There is evidence too that the homosexual subculture is relatively promiscuous with $40 \%$ of the respondents in a Beijing study having more than 10 sexual partners. ${ }^{25}$ As homosexuality becomes more 
socially acceptable and less stigmatised, so syphilis may become more prevalent in this group, with obvious implications for disease control.

\section{Population mobility}

A further important driver of syphilis resurgence is the new mobility of the population with ease of movement across borders and within the country, which was almost unknown in the Mao years. This movement takes two major forms: migration on a long-term basis for work, and short-term travel predominantly for business and tourism. Since the late 1980s, the Chinese government started to lift travel restrictions so that rural peasants can move to the cities to find work. The number of rural-urban migrants increased from 50 million in 1990 to 120 million in 2000, with an estimate of 160 million by $2010 .{ }^{48}$ It has been assumed that migrants are creating a demand for the sex industry and spreading STDs and HIV. ${ }^{19,38}$ Evidence from other countries shows that the sex industry thrives around communities of migrant workers who are predominantly men. ${ }^{49}$ But there is limited hard evidence that Chinese migrants are spreading STDs. Although some of the major receiving centres for migrant workers, such as Zhejiang and Fujian, have higher incidences of syphilis, not all do, and Guangxi, which is among the provinces with the highest incidence, receives very few migrants. ${ }^{48}$ The one study specifically to address this question of migration and syphilis was carried out in Hangzhou, the capital city of Zhejiang Province. The prevalence of syphilis among migrants in the study was lower $(0.48 \%)$ than in the urban population $(0.68 \%)$. In addition, it was found that $48 \%$ of the migrants were women and $43 \%$ of all migrants had migrated with a partner. $^{49}$

More important in terms of fuelling the syphilis epidemic is the huge number of relatively wealthy business people (mostly men) now on the move in China. ${ }^{34}$ A study among sex workers in brothels in Yunnan Province found that almost all of the clients were businessmen from outside. ${ }^{22}$ The massive growth in the sex industry has been partly driven by this new easy mobility.

\section{Cost of health care}

The third important driver of the syphilis epidemic is the collapse of universal free health care and much of the public health infrastructure, along with the introduction of economic reforms from the late 1970 s. ${ }^{50}$ The current health system in China is largely privatised with many people, especially in rural areas, paying out-of-pocket for health care. This means that some of the most vulnerable do not seek health care, with syphilis sufferers left untreated, at risk of major health problems, and a source of its spread. ${ }^{51,52}$ For example, a study carried out in a rural area outside Beijing found that $80 \%$ of women with genitourinary symptoms did not attend for health care partly because of fear of the cost and partly because of poor understanding of the importance of the problem. ${ }^{53}$ In addition, privatisation has led to varying standards of health care, especially in terms of diagnostics, so that untreated infection continues to spread in the community. ${ }^{51}$

\section{Conclusion}

The Chinese succeeded once in eradicating syphilis but that was in a very different political and social climate. A return to centralised programmes that ignore the rights of individuals is not desirable or feasible in present-day China. But there are lessons to be learned from the earlier experience and a number of measures can be taken to reverse the epidemic trend.

First, there must be high-level political commitment. This was crucial to the earlier success in the 1950s. The Chinese already have demonstrated high-level commitment to improving some infectious disease control programmes, for HIV, then SARS (severe acute respiratory syndrome), and for avian influenza. Syphilis should be included in China's priorities for health.

Second, a cornerstone of the earlier success was accessible, affordable screening, and free treatment. Given the current high prevalence in certain groups, notably MSM, FSWs, and IDUs, screening programmes could at the very least start there. ${ }^{54}$ However, given the illegal and stigmatised nature of these risk behaviours, offering free screening and treatment is not straightforward, ${ }^{55}$ and uptake would probably be patchy. As far as population screening goes, the Chinese have just foregone a good opportunity. Until October 2003, screening for syphilis was frequently included in the then compulsory premarital examination, ${ }^{35}$ and treatment had to be completed before the marriage could take place. As it became voluntary, the number of couples undertaking screening has dropped dramatically. It is just starting to be recognised that the premarital examination performed a very useful public health function for screening for disease and for health promotion in young adults, and one province (Heilongjiang) has re-introduced it in its compulsory form, with other provinces also considering this course of action. Others are expected to follow. Screening of pregnant women is obviously crucial because of the devastating effects of congenital syphilis. Free screening was introduced in Shenzhen and this has proved costeffective and sustainable, ${ }^{52}$ but it should be scaled up across the country.

Third, the huge resources that have been allocated to free HIV voluntary counselling and testing (VCT) programmes throughout the country should be extended to screen for syphilis. Given that the prevalence of syphilis is 10 times higher, the transmission easier, and the treatment effective, it seems extraordinary that it has been largely ignored in the huge programmes devoted to HIV. Many of these VCT centres are greatly underused at present, so to widen their remit to include syphilis could be done at low cost. This anomaly is not unique to China. It has been noted that in parts of sub-Saharan Africa individuals are treated for HIV while their syphilis is ignored. ${ }^{56}$ 
Fourth, clearly awareness of the threat of syphilis needs to be raised. The Chinese have done an extraordinary job in this regard for HIV: awareness of HIV is high among most population groups, especially the young. ${ }^{57-60}$ But much less is known about syphilis. ${ }^{61-64}$ Education of health providers and the general public should be the cornerstone. Promotion of condom use, especially in high-risk groups must be a key message. This is important, all the more, for FSWs who have sexual contact with large numbers of men. Condom use varies across studies and among different types of sex worker, but 'always' condom use averages at around one-third across key studies. ${ }^{29,64,65}$ Pilot programmes of $100 \%$ condom use in Jiangsu, Hubei, Hunan, Guangxi, and Hainan provinces have demonstrated reductions in the prevalence of syphilis in FSWs, ${ }^{66}$ and these programmes could be scaled up across the country. The other group that must be targeted for condom use is MSM. In the context of HIV/AIDS, considerable efforts are being made to target MSM, especially in bars and clubs, but they remain a difficult group to access, and there are no published reports about effective means of increasing condom use in MSM in China.

It has been suggested that the elimination of syphilis in the developed world is a realistic objective. ${ }^{67}$ With the acceleration in increase in the incidence now probably slowing in China, ${ }^{14}$ it is not inconceivable that with focused measures, such as those suggested, China could achieve important reductions in syphilis incidence in the near future.

\section{Acknowledgements Search strategy}

We searched MEDLINE from 1990 to 2007 for published work relevant to this subject. The search was restricted to English language papers and those in Chinese with abstracts in English. The primary search terms were 'China' and 'syphilis'. Secondary search terms were 'epidemiology', 'incidence', 'prevalence', 'STD', 'risk factor', 'sexual behaviour', 'sex workers', 'drug user', and 'migration' in various combinations. We mainly selected publications from the past 10 years, but did not exclude commonly referenced older publications. We also searched the reference lists and selected additional articles. Finally, we searched relevant reports from the Chinese Ministry of Health, UNAIDS, and WHO.

\section{Author contributions}

All authors contributed equally to the development, intellectual concepts, and writing of this paper.

\section{Competing interests}

The authors have no competing interests.

Provenance and peer review

Commissioned without payment; externally peer reviewed.

\section{References}

1 Fisman DN. Syphilis resurgent in China. Lancet 2007;369:84-5.

2 French P. Syphilis. BMJ 2007;334:143-7.

3 Golden MR, Marra CM, Holmes KK. Update on syphilis: resurgence of an old problem. JAMA 2003;290:1510-14.

4 Walker DG, Walker GJ. Forgotten but not gone: the continuing scourge of congenital syphilis. Lancet Infect Dis 2002;2:432-6.

5 Weir E, Fisman D. Syphilis: have we dropped the ball? CMAJ 2002;167:1267-8.

6 Buchacz K, Patel P, Taylor M, Kerndt PR, Byers RH, Holmberg SD, et al. Syphilis increases viral load and decreases CD4 cell counts in HIVinfected patients with new syphilis infections. AIDS 2004;18:2075-9.

7 Reynolds SJ, Risbud AR, Shepherd ME, Rompalo AM, Ghate MV, Godbole SV, et al. High rates of syphilis among STI patients care contributing to the spread of HIV-1 in India. Sex Transm Infect 2006;82:121-6.

8 Cohen MS, Henderson GE, Aiello P, Zheng H. Successful eradication of sexually transmitted diseases in the People's Republic of China: implications for the 21st century. J Infect Dis 1996;174:223-9.

9 Horn J. Away with all pests: an English surgeon in the People's Republic of China. Monthly Review Press: New York, 1974.

10 Hesketh T, Zhu WX. Health in China: from Mao to market reform. BMJ 1997;314:1543-5.

11 Sidel VW. The barefoot doctors of the People's Republic of China. N Engl J Med 1972;286:1292-300.

12 Cohen MS, Gao P, Fox K, Henderson G. Sexually transmitted diseases in the People's Republic of China in Y2K: back to the future. Sex Transm Dis 2000;27:143-5.

13 Gong XD, Zhang GC, Ye SZ, Wu QD, Zhu X et al. Epidemiological analysis of syphilis in China from 1985 to 2000. Chin J Sex Transm Infect 2001;1:1-6.

14 Lin CC, Gao X, Chen XS, Chen Q, Cohen MS. China's syphilis epidemic: a systematic review of seroprevalence studies. Sex Transm Dis 2006;33:726-36.

15 Chen X, Gong X, Liang G, Zhang G. epidemiological trends of sexually transmitted diseases in China. Sex Transm Dis 2000;27:138-42.

16 Chen ZQ, Zhang GC, Gong XD, Lin C, Gao X, Liang GJ, et al. Syphilis in China: results of a national surveillance programme. Lancet 2007;369:132-8.

17 Centre for Disease Control and Prevention. STD surveillance 2006. Available at http://www.cdc.gov/std/stats/trends2006, accessed on 1 December 2007.

18 WHO. Sexually transmitted infections in South-East Asia. Available at http://www.searo.who.int/Linkfiles/World_Aids_Day, accessed on 1 December 2007.

19 UNAIDS. 2005 Present AIDS epidemic situation in China. Available at http://www.unchina.org/unaids/. Accessed 1 December 2007.

20 Gil VE, Wang MS, Anderson AF, Lin GM, Wu ZO. Prostitutes, prostitution and STD/HIV transmission in Mainland China. Soc Sci Med 1996;42:141-52.

21 van den Hoek A, Yuliang F, Dukers NH, Zhiheng C, Jiangting F, Lina Z, et al. High prevalence of syphilis and other sexually transmitted diseases among FSWs in China: potential for fast spread of HIV. AIDS 2001;15:753-9.

22 Hesketh T, Zhang J, Dong JQ. HIV knowledge and risk behaviour of female sex workers in Yunnan Province, China. AIDS Care 2005; 17:958-66.

23 Low N, Broutet N, Adu-Sarkodie Y, Barton P, Hossain M, Hawkes S. Global control of sexually transmitted infections. Lancet 2006;368:1960-1.

24 Sciarra JJ. Sexually transmitted diseases: global importance. Int J Gynaecol Obstet 1997;58:107-19.

25 Ruan Y, Li D, Li X, Qian HZ, Shi W, Zhang X, et al. Relationship between syphilis and HIV infections among men who have sex with men in Beijing, China. Sex Transm Dis 2007;34:592-7.

26 Choi KH, Ning Z, Gregorich SE, Pan QC. The influence of social and sexual networks in the spread of HIV and syphilis in men 
who have sex with men in Shanghai, China. J Acquir Immune Defic Syndr 2007;45:77-84.

27 He Q, Wang Y, Lin P, Liu Y, Yang F, Fu X, et al. Potential bridges for HIV infection to men who have sex with men in Guangzhou, China. AIDS Behav 2006;10:S17-23.

28 Jiang J, Cao N, Zhang J, Xia Q, Gong X, Xue H, et al. High prevalence of sexually transmitted diseases among men who have sex with men in Jiangsu Province, China. Sex Transm Dis 2006;33: 118-23.

29 Ruan Y, Cao X, Qian HZ, Zhang L, Qin G, Jiang Z, et al. Syphilis among female sex workers in southwestern China: potential for HIV transmission. Sex Transm Dis 2006;33:726-36.

30 Tian LG, Ma ZE, Ruan YH, Cao XY, Huang JP, Wang DR, et al. Incidence rates of HIV and syphilis in female sex workers with heavy drug use in Sichuan province China. Zhonghua Liu Xing Bing Xue Za Zhi 2006;27:939-42.

31 Lu F, Wang N, Wu Z, Sun X, Rehnstrom J, Poundstone K, et al. Estimating the number of people with HIV in China in 2005: methods and results. Sex Transm Infect 2006;82:87-91.

32 Pourbohluol B, Rekart ML, Brunham RC. Impact of mass treatment on syphilis transmission: a mathematical modeling approach. Sex Transm Dis 2003;30:297-305.

33 Grassly NC, Fraser C, Garnett GP. Host immunity and synchronised epidemics of syphilis across the United States. Nature 2005; 433:417-21.

34 Zhang K, Li D, Li H, Beck EJ. Changing sexual attitudes and behaviour in China: implications for the spread of HIV and other sexually transmitted diseases. AIDS Care 1999;11:581-9.

35 Hesketh T. Getting married Chinese style: pass the medical first. BMJ 2003;326:277-9.

$36 \mathrm{Qu}$ JD, Hesketh T. Family size, sex ratio and fertility preferences in the era of the One Child Family Policy: results from the National Family Planning and Reproductive Health Survey. BMJ 2006;333: 371-3.

37 Hesketh T. Abnormal sex ratios in human populations: causes and consequences. Proc Natl Acad Sci USA 2006;103: 13271-5.

38 Tucker JD, Henderson GE, Wang TF, Huang YY, Parish W, Pan SM, et al. Surplus men, sex work and the spread of HIV in China. AIDS 2003;19:539-47.

39 Hudson V, Den Boer A. A surplus of men, a deficit of peace: security and sex ratios in Asia's largest states. Int Secur 2002;26:5-38.

$40 \mathrm{He} \mathrm{N}$, Detels R, Chen Z, Jiang Q, Zhu J, Wu M, et al. Sexual behaviour among employed male rural migrants in Shanghai, China. AIDS Educ Prev 2006;18:176-86.

41 Xia DY, Liao SS, He QY, Liao JF, Wang XC, Wu QH. A questionnaire-based survey on attitude and behaviour of sex among rural women in Hainan Province. Zhonghua Liu Xing Bing Za Zhi 2004;25:586-9.

$42 \mathrm{Hu} \mathrm{Z}$, Wang D, Liu H, Yang S, Ye D, Cao H, et al. STD/AIDS knowledge, attitude, practice and characteristics of market vendors in Hefei, China. AIDS Patient Care STDS 2005;19: $121-6$.

43 Hu Z, Liu H, Li X, Stanton B, Chen X. HIV-related sexual behaviour among migrants and non-migrants in a rural area of China: role of rural-to-urban migration. Public Health 2006;120:339-45.

$44 \mathrm{Ma} \mathrm{Q}$, Ono-Kihara M, Cong L, Xu G, Zamani S, Ravari SM, et al. Sexual behaviour and awareness of Chinese university students in transition with implied risk of STDs and HIV: a cross-sectional study. BMC Public Health 2006;6:232.

45 Zhang L, Gao X, Dong Z, Tan Y, Wu Z. Premarital sexual activities among students in a university in Beijing China. Sex Transm Dis 2002;29:212-15
46 Chen B, Wang LP, Wang HX, Han YF, Zhao XM, Ma QL, et al. Survey on reproductive health status of Shanghai college students. Zhonghua Nan Ke Xue 2005;11:744-7.

47 Qian HZ, Vermund SH, Wang N. Risk of HIV/AIDS in China: subpopulations of special importance. Sex Transm Infect 2005;81: 442-7.

48 National Bureau of Statistics of China. (NBSC) 2002 Statistics of the Fifth National Census in 2000. Available at http://www. china.org.cn, accessed on 1 September 2006.

49 Hesketh T, Li L, Ye X, Wang H, Jiang M, Tomkins A. HIV and syphilis in migrant workers in eastern China. Sex Transm Infect 2006;82:11-14.

50 Blumenthal D, Hsiao W. Privatization and its discontents: the evolving Chinese health care system. N Engl J Med 2005;353:1165-70.

51 Hesketh T, Huang XM, Wang ZB, Zhu WX, Cubitt DW, Williams $\mathrm{D}$, et al. HIV and syphilis in young Chinese adults: implications for spread. Int J STD AIDS 2005;16:262-6.

52 Cohen MS, Hawkes S, Mabey D. Syphilis returns to China with a vengeance. Sex Transm Dis 2006;33:724-5.

53 Zhang HJ, Gao SY, Li FI, Qin Y, Zeng G. Analysis on the situation of STI prevalence and behaviour of health care seeking in married women in Miyun county. Chin J Fam Plann 2002;5:273-6.

54 Steen R, Dallabetta G. Sexually transmitted infection control with FSWs: regular screening and presumptive treatment augment effort to reduce risk and vulnerability. Reprod Health Matters 2003; 11:74-90.

55 Vermund SH, Wilson CM. Barriers to HIV testing. Where next? Lancet 2002;360:1186-7.

56 Peeling RW, Mabey D, Fitzgerald DW, Watson-Jones D. Avoiding HIV and dying of syphilis. Lancet 2004;364:1561-3.

57 Hesketh T, Lin D, Li H, Tomkins AM. Attitudes to HIV and its testing in high prevalence areas of China: informing voluntary counselling and testing. Sex Transm Infect 2005;81:108-12.

58 Chen J, Choe MK, Chen S, Zhang S. The effects of individual and community level knowledge, beliefs and fear on stigmatization of people living with HIV/AIDS in China. AIDS Care 2007;19:666-73.

59 Hong Y, Li X, Mao R, Stanton B. Internet use among Chinese college students: implications for sex education and HIV prevention. Cyberpsychol Behav 2007;10:161-9.

60 Lonn E, Sahlholm K, Maimaiti R, Abdukarim K, Andersson R. A traditional society in change encounters HIV/AIDS: knowledge, attitudes and risk behaviour among students in northwestern China. AIDS Patient Care STDS 2007;21:48-56.

61 Liao SS, Schensul J, Wolffers I. Sex-related health risks and implications for interventions with hospitality women in Hainan China. AIDS Educ Prev 2003;15:109-21.

62 Lou CH, Zhao Q, Gao ES, Shah IH. Can the Internet be used effectively to provide sex education to young people in China? $J$ Adolesc Health 2006;39:720-8.

63 Yang H, Li X, Stanton B, Fang X, Lin D, Naar-King S. HIV-related knowledge, stigma and willingness to disclose: a medication analysis. AIDS Care 2006;18:717-24.

64 Lau JT, Tsui HY, Siah P, Zhang KL. A study in female FSWs in southern China (Shenzhen): HIV-related knowledge, condom use and STD history. AIDS Care 2002;14:219-33.

65 Hesketh T, Zhang J, Dong JQ. HIV knowledge and risk behaviour of female sex workers in Yunnan Province, China. AIDS Care 2005; 17:958-66.

66 World Health Organisation. Experience of the 100\% condom use programme in selected countries of Asia. Geneva World Health Organisation. WHO: Geneva, Switzerland, 2004. pp 19-20.

67 Rompalo AM. Can syphilis be eradicated from the world? Curr Opin Infect Dis 2001;14:41-44. 